\title{
Extension of a Noninteractive Reliability Model for Ceramic Matrix Composites
}

Stephen F. Duffy

Cleveland State University, s.duffy@csuohio.edu

Robert C. Wetherhold

State University of New York at Buffalo

Lalit K. Jain

State University of New York at Buffalo

Follow this and additional works at: https://engagedscholarship.csuohio.edu/encee_facpub

Part of the Structures and Materials Commons

How does access to this work benefit you? Let us know!

\section{Recommended Citation}

Duffy, Stephen F.; Wetherhold, Robert C.; and Jain, Lalit K., "Extension of a Noninteractive Reliability Model for Ceramic Matrix Composites" (1990). Civil and Environmental Engineering Faculty Publications. 2.

https://engagedscholarship.csuohio.edu/encee_facpub/2

This Report is brought to you for free and open access by the Civil and Environmental Engineering at EngagedScholarship@CSU. It has been accepted for inclusion in Civil and Environmental Engineering Faculty Publications by an authorized administrator of EngagedScholarship@CSU. For more information, please contact library.es@csuohio.edu. 
NASA Contractor Report 185267

\section{Extension of a Noninteractive Reliability Model for Ceramic Matrix Composites}

Stephen F. Duffy

Cleveland State University

Cleveland, Ohio

and

Robert C. Wetherhold and Lalit K. Jain

State University of New York at Buffalo

Buffalo, New York

August 1990

Prepared for

Lewis Research Center

Under Cooperative Agreement NCC3-89 and Grant NAG3-862

\section{N/Sก}

National Aeronautics and

Space Administration

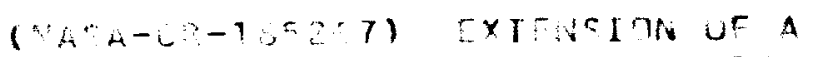

WONITTSACTIV PELIASILTTY MONEL FUR CIERAMIC

MATPIX COMPSuIEs Final kronte crlaveland

statsunive in $n$ csil 110

$\begin{array}{rl} & \text { unclins } \\ 63 / 27 & 0245193\end{array}$ 



\title{
EXTENSION OF A NONINTERACTIVE RELIABILITY MODEL FOR CERAMIC MATRIX COMPOSITES
}

\author{
Stephen F. Duffy \\ Department of Civil Engineering \\ Cleveland State University \\ Cleveland, Ohio 44115 \\ Robert C. Wetherhold and Lalit K. Jain \\ Department of Mechanical and Aerospace Engineering \\ State University of New York \\ Buffalo, New York 14260
}

\section{INTRODUCTION}

In the next decade ceramic composites will increasingly be used as high-temperature components in advanced gas turbines. Ceramic components will allow an increase in the operating temperature of the gas stream (measured by the turbine entry temperature), thereby resulting in greater fuel economy in aerospace and automotive turbine applications. Since these materials will be produced from abundant nonstrategic materials, computational structural mechanics methods are evolving to keep pace with this technology. As a result, establishing protocols for sound design methodology, which is the subject of this technical note, is the focus of much current analytical research.

Our objective was to extend a reliability model proposed by Duffy and Manderscheid (1989) for orthotropic ceramic composites. Their approach used tensorial invariant theory to develop an integrity basis from which a subset of invariants was created to incorporate material anisotropy. Herein we propose a different subset of the original integrity basis and construct a more general scalar failure function. The assumption that the failure of a component is governed by its weakest link leads to a formulation that is similar in nature to the principle of independent action (PIA) model for monolithic ceramics. Note that this is a continuum approach to reliability analysis in that it excludes any detailed interaction between individual constituents. 


\section{EXTENSION OF THE RELIABILITY MODEL}

Consider a volume whose failure is assumed to be governed by its weakest link. Under this assumption, events leading to failure of a given link do not affect other links (see, for example, Batdorf and Heinisch (1978), Wetherhold (1983), and Cassenti (1984)); thus component reliability is given by the following expression:

$$
\mathrm{R}=\exp \left[-\int_{\mathrm{V}} \psi \mathrm{dV}\right]
$$

Here, $\psi\left(x_{i}\right)$ is the failure function per unit volume at position $x_{i}$ within the component, and $V$ is the component volume. Note that the lower case Roman letter subscripts denote tensor indices with an implied range from 1 to 3 . For orthotropic composites, the failure function must reflect the stress state and the appropriate material symmetry. This requires that

$$
\psi=\psi\left(\sigma_{\mathrm{ij}}, \mathrm{a}_{\mathrm{i}}, \mathrm{b}_{\mathrm{i}}\right)
$$

where $a_{i}$ and $b_{i}$ are orthogonal unit vectors that represent the local principal material directions, and $\sigma_{\mathrm{ij}}$ represents the Cauchy stress tensor. The sense of $\mathrm{a}_{\mathrm{i}}$ and $\mathrm{b}_{\mathrm{i}}$ is immaterial; thus their influence is taken through the products $a_{i} a_{j}$ and $b_{i} b_{j}$, that is

$$
\psi=\psi\left(\sigma_{\mathrm{ij}}, \mathrm{a}_{\mathrm{i}} \mathrm{a}_{\mathbf{j}}, \mathrm{b}_{\mathrm{i}} \mathrm{b}_{\mathrm{j}}\right)
$$

Since the stress and local preferred directions may vary from point to point in the component, equation (3) implies that the stress field $\sigma_{i j}\left(x_{k}\right)$ and unit vector fields $a_{i}\left(x_{k}\right)$ and $b_{i}\left(x_{k}\right)$ must be specified to define $\psi$.

Because $\psi$ is a scalar function, it must remain form invariant under arbitrary proper orthogonal transformations. Work by Reiner (1945), Rivlin and Smith (1969), Spencer (1971) and others demonstrated that by applying the Cayley-Hamilton theorem and the elementary properties of tensors, a finite set of invariants, known as an integrity basis, can be developed. Form invariance of $\psi$ is ensured if $\psi$ depends on invariants that constitute either the integrity basis or any subset thereof. We are not reporting the first practical application of this approach in formulating models that are functionally dependent on stress and material direction. Others who 
have used this methodology are the following: Lance and Robinson (1971), who proposed a maximum shear stress plasticity theory for composites; Boehler and Sawczuk (1977), who proposed a plasticity theory for anisotropic cohesive materials; Arnold (1989), who developed a thermoelastic constitutive theory for transversely isotropic materials; and Robinson and Duffy (1990), who developed a viscoplastic constitutive theory for this same class of materials. Clearly, our direction here is not without precedent.

Adapting the previously mentioned work to $\psi$ gives an integrity basis composed of twenty-eight tensor products. Following arguments similar to those of Spencer (1984), we find that several of these tensor products are equal and others are trivial identities such that the final integrity basis for $\psi$ contains only the invariants

$$
\begin{gathered}
I_{1}=\sigma_{\mathrm{ij}} \\
\mathrm{I}_{2}=\sigma_{\mathrm{ij}} \sigma_{\mathrm{ji}} \\
\mathrm{I}_{3}=\sigma_{\mathrm{ij}} \sigma_{\mathrm{jk}} \sigma_{\mathrm{ki}} \\
\mathrm{I}_{4}=\mathrm{a}_{\mathrm{i}} \mathrm{a}_{\mathrm{j}} \sigma_{\mathrm{ji}} \\
\mathrm{I}_{5}=\mathrm{a}_{\mathrm{i}} \mathrm{a}_{\mathrm{j}} \sigma_{\mathrm{jk}} \sigma_{\mathrm{ki}} \\
\mathrm{I}_{6}=\mathrm{b}_{\mathrm{i}} \mathrm{b}_{\mathrm{j}} \sigma_{\mathrm{ji}}
\end{gathered}
$$

and

$$
\mathrm{I}_{7}=\mathrm{b}_{\mathrm{i}} \mathrm{b}_{\mathrm{j}} \sigma_{\mathrm{jk}} \sigma_{\mathrm{ki}}
$$

From this group we can construct a subset of invariants that correspond to the stress components oriented to the principal material direction. This new set of invariants includes

$$
\begin{aligned}
& \hat{\mathrm{I}}_{1}=\mathrm{I}_{4} \\
& \hat{\mathrm{I}}_{2}=\mathrm{I}_{6}
\end{aligned}
$$




$$
\begin{gathered}
\hat{\mathrm{I}}_{3}=\mathrm{I}_{1}-\mathrm{I}_{4}-\mathrm{I}_{6} \\
\hat{\mathrm{I}}_{4}=\left[\left(2 \mathrm{I}_{5}-\mathrm{I}_{4}^{2}-\mathrm{I}_{6}^{2}-\mathrm{I}_{2}+2 \mathrm{I}_{7}+\hat{\mathrm{I}}_{3}^{2}\right) / 2\right]^{1 / 2} \\
\hat{\mathrm{I}}_{5}=\left[\left(-2 \mathrm{I}_{5}+\mathrm{I}_{4}^{2}-\mathrm{I}_{6}^{2}+\mathrm{I}_{2}-\hat{\mathrm{I}}_{3}^{2}\right) / 2\right]^{1 / 2}
\end{gathered}
$$

and

$$
\hat{\mathrm{I}}_{6}=\left[\left(-2 \mathrm{I}_{7}-\mathrm{I}_{4}^{2}+\mathrm{I}_{6}^{2}+\mathrm{I}_{2}-\hat{\mathrm{I}}_{3}^{2}\right) / 2\right]^{1 / 2}
$$

For a uniformly stressed unit volume (or in the context of Weibull analysis, a single link) the first three invariants correspond to the magnitudes of the normal stress components. Note that $\hat{\mathrm{I}}_{3}$ corresponds to the magnitude of the normal stress component in the direction defined by the cross product of vectors $a_{j}$ and $b_{k}$, that is

$$
d_{i}=e_{i j k} a_{j} b_{k}
$$

where $e_{i j k}$ is the permutation tensor. The last three invariants in the subset correspond to magnitudes of the shear stress components. (Refer to Fig. 1 for a pictorial representation of the invariants.) A fundamental difference between the theory proposed here and that of the original work by Duffy and Manderscheid (1989) lies in the number of invariants derived from the original integrity basis. The previous model employed only five invariants and suppressed the dependence of $\psi$ on invariants $\mathrm{I}_{2}$ and $\mathrm{I}_{3}$. The current formulation uses six invariants and includes $\mathrm{I}_{2}$, but it is still independent of $\mathrm{I}_{3}$. The additional parameter arises from a different and apparently more consistent set of assumptions. Taking

$$
\psi=\psi\left(\hat{\mathrm{I}}_{1}, \hat{\mathrm{I}}_{2}, \hat{\mathrm{I}}_{3}, \hat{\mathrm{I}}_{4}, \hat{\mathrm{I}}_{5}, \hat{\mathrm{I}}_{6}\right)
$$

ensures $\psi$ is form invariant.

If we assume that compressive stresses associated with normals $\hat{I}_{1}, \hat{I}_{2}$, and $\hat{I}_{3}$ do not contribute to failure, then 


$$
\begin{aligned}
& \left\langle\hat{\mathrm{I}}_{1}\right\rangle= \begin{cases}\hat{\mathrm{I}}_{1} & \hat{\mathrm{I}}_{1}>0 \\
0 & \hat{\mathrm{I}}_{1} \leq 0\end{cases} \\
& \left\langle\hat{\mathrm{I}}_{2}\right\rangle= \begin{cases}\hat{\mathrm{I}}_{2} & \hat{\mathrm{I}}_{2}>0 \\
0 & \hat{\mathrm{I}}_{2} \leq 0\end{cases} \\
& \left\langle\hat{\mathrm{I}}_{3}\right\rangle= \begin{cases}\hat{\mathrm{I}}_{3} & \hat{\mathrm{I}}_{3}>0 \\
0 & \hat{\mathrm{I}}_{3} \leq 0\end{cases}
\end{aligned}
$$

In addition, the shear stress contribution is sign-insensitive; thus

$$
\begin{aligned}
& \left\langle\hat{\mathrm{I}}_{4}\right\rangle=\left|\hat{\mathrm{I}}_{4}\right| \\
& \left\langle\hat{\mathrm{I}}_{5}\right\rangle=\left|\hat{\mathrm{I}}_{5}\right| \\
& \left\langle\hat{\mathrm{I}}_{6}\right\rangle=\left|\hat{\mathrm{I}}_{6}\right|
\end{aligned}
$$

for all values of $\hat{I}_{4}, \hat{I}_{5}$, and $\hat{I}_{6}$. At this point we assume that the stress components identified by the aforementioned invariants act independently in producing failure (i.e., a non-interactive theory). Following reasoning similar to that of Wetherhold (1983), we find that $\psi$ takes the form

$$
\begin{aligned}
\psi=\left[\frac{\left\langle\hat{\mathrm{I}}_{1}\right\rangle}{\beta_{1}}\right]^{\alpha_{1}}+\left[\frac{\left\langle\hat{\mathrm{I}}_{2}\right\rangle}{\beta_{2}}\right]^{\alpha_{2}}+\left[\frac{\left\langle\hat{\mathrm{I}}_{3}\right\rangle}{\beta_{3}}\right]^{\alpha_{3}} \\
+\left[\frac{\left\langle\hat{\mathrm{I}}_{4}\right\rangle}{\beta_{4}}\right]^{\alpha_{4}}+\left[\frac{\left\langle\hat{\mathrm{I}}_{5}\right\rangle}{\beta_{5}}\right]^{\alpha_{5}}+\left[\frac{\left\langle\hat{\mathrm{I}}_{6}\right\rangle}{\beta_{6}}\right]^{\alpha_{6}}
\end{aligned}
$$

The $\alpha$ 's associated with each invariant correspond to the Weibull shape parameters, and the $\beta$ 's correspond to Weibull scale parameters. Inserting equation (25) into the volume integration given by equation (1) along with equations (19) to (24) yields a reliability model for an orthotropic ceramic composite subject to a three-dimensional state of stress.

\section{CONCLUDING REMARKS}

In this technical note we have proposed a more general reliability model for ceramic composites with orthotropic material symmetry. This approach allows material orientation within 
a component to vary along a family of curves such that the material is locally orthotropic. The model was constructed by using an invariant formulation. Such an approach indicates the maximum number and form of stress invariants necessary to define the failure function $\psi$. A subset of the integrity basis for $\psi$ was constructed with invariants that correspond to the stress components in the principal material orientation. The result is a model similar in nature, yet different in form, to the PIA theory for monolithic ceramics. This model can be readily integrated with the finite element methods of structural analysis. Using the stress output from a finite element analysis allows component integrity to be computed by calculating element-by-element reliability. On the basis of the weakest link concept then, the component survivability is simply the product of individual element reliabilities. The model could be easily integrated into a computer algorithm such as SCARE (Structural Ceramics Analysis and Reliability Evaluation, Gyekenyesi (1986)).

\section{REFERENCES}

Arnold, S. M., 1989, "A Transversely Isotropic Thermoelastic Theory," NASA TM-101302.

Batdorf, S. B. and Heinisch., H. L., Jr., 1978, "Weakest Link Theory Reformulated for Arbitrary Fracture Criterion," Journal of the American Ceramic Society, Vol. 61, No. 7-8, pp. 355-358.

Boehler, J. P. and Sawczuk, A., 1977, "On Yielding of Oriented Solids," Acta Mechanica, Vol. 27, No. 1-4, pp. 185-204.

Cassenti, B. N., 1984, "Probabilistic Static Failure of Composite Material," Journal, Vol. 22, No. 1, pp. 103-110. 
Duffy, S. F. and Manderscheid, J. M., 1989 "Noninteractive Macroscopic Reliability Model for Ceramic Matrix Composites with Orthotropic Material Symmetry," ASME Paper 89-GT-129, (Also, NASA TM-101414).

Gyekenyesi, J. P., 1986, "SCARE: A Postprocessor Program to MSC/NASTRAN for Reliability Analysis of Structural Ceramic Components," Journal of Engineering for Gas Turbines and Power, Vol. 108, No. 3, pp. 540-546.

Lance, R. H. and Robinson, D. N., 1971, "A Maximum Shear Stress Theory of Plastic Failure of Fiber-Reinforced Materials," Journal of the Mechanics and Physics of Solids, Vol. 19, No. 2 , pp. $49-60$.

Reiner, M., 1945, "A Mathematical Theory of Dilatancy," American Journal of Mathematics, Vol. 67, pp. 350-362.

Robinson, D. N. and Duffy, S. F., 1990, "Continuum Deformation Theory for High-Temperature Metallic Composites," Journal of Engineering Mechanics, Vol. 116, No. 4, pp. 832-844.

Rivlin, R. S. and Smith, G. F., 1969, "Orthogonal Integrity Basis for N Symmetric Matrices," Contributions to Mechanics, D. Abir, ed., Pergamon Press, Oxford, pp. 121-141.

Spencer, A. J. M., 1971, "Theory of Invariants," Continuum Physics - Vol. IMathematics, A. C. Eringen, ed., Academic Press, New York, pp. 239-255.

Spencer, A. J. M., 1984, "Constitutive Theory for Strongly Anisotropic Solids," Continuum Theory of the Mechanics of Fibre-Reinforced Composites, A. J. M. Spencer, ed., Springer-Verlag, New York, pp. 1-32. 
Wetherhold, R. C., 1983, "Statistics of Fracture of Composite Materials Under Multiaxial Loading," Ph.D. Thesis, University of Delaware.
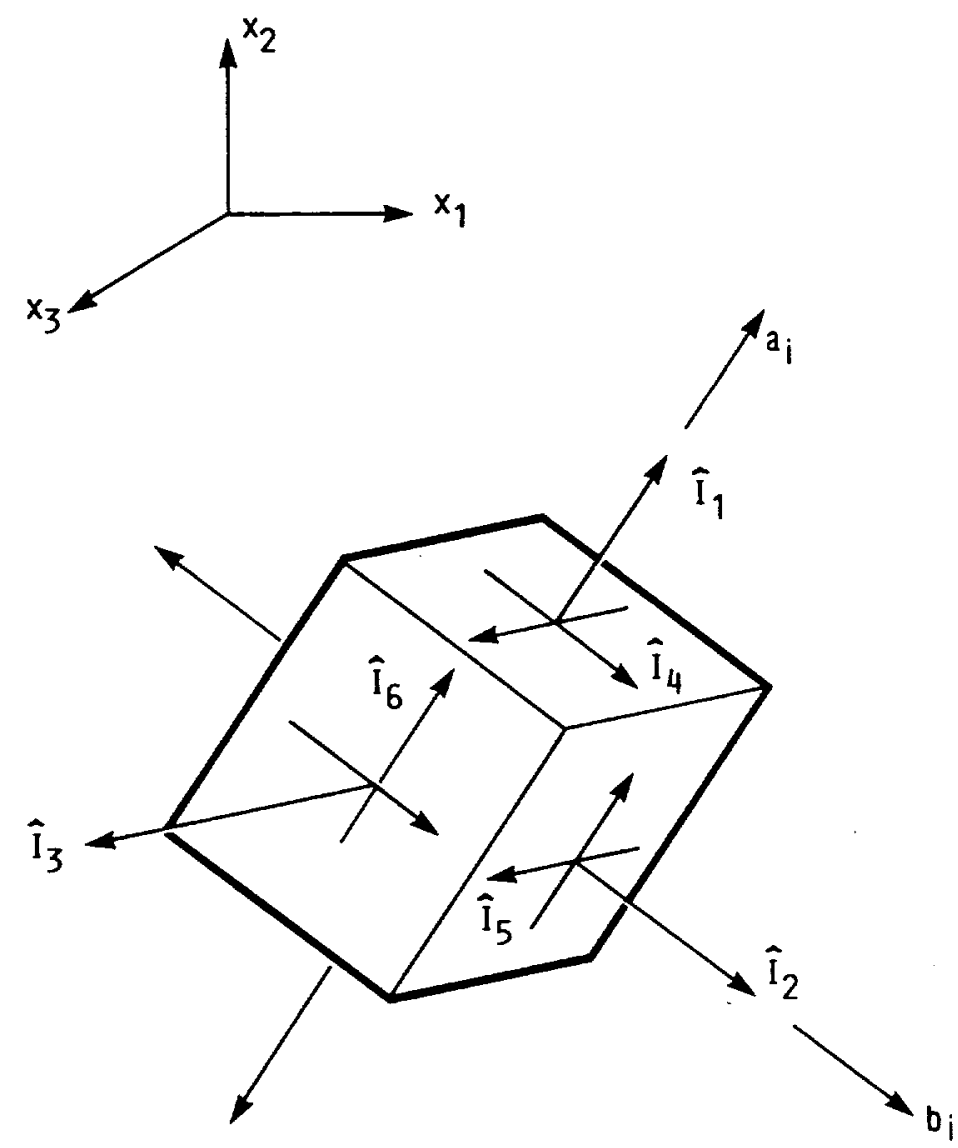

Fig. 1 Physical interpretations of the invariants. 


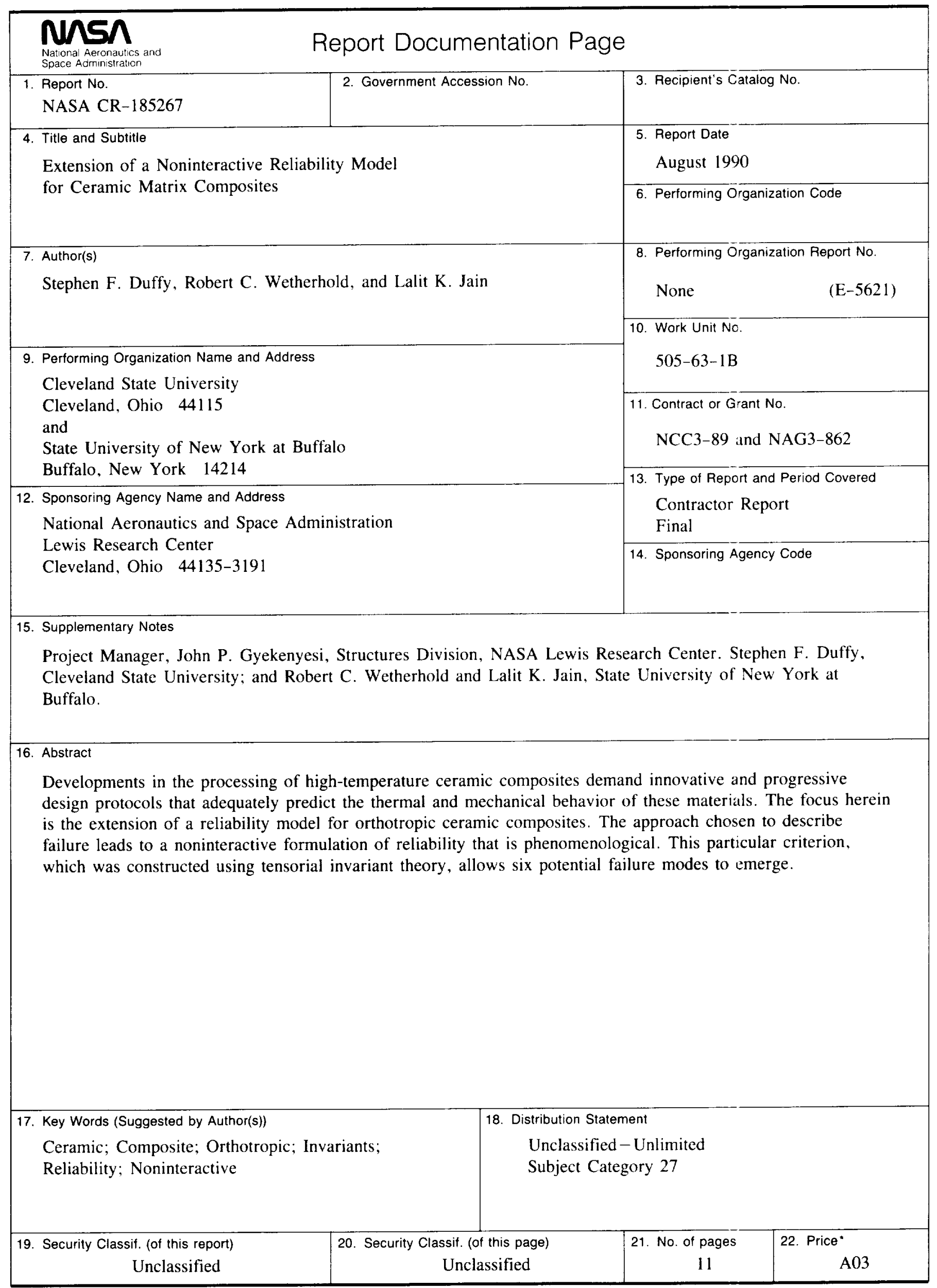


